\title{
The impact of a short course of three lipid lowering drugs on fat oxidation during exercise in healthy volunteers
}

\author{
A. Head, P.M. Jakeman' ${ }^{1}$ M.J. Kendall, R. Cramb and S. Maxwell \\ Department of Medicine and 'Applied Physiology Research Unit, University of Birmingham, Birmingham, \\ $U K$
}

Summary: We examined the impact of three lipid lowering drugs on fat oxidation during a 120 minute treadmill walk, at an exercise intensity of $50 \%$ maximal oxygen uptake $\left(V_{2}\right.$ max $)$. Subjects $(N=24)$ were healthy male volunteers with normal serum chemistry, assigned to three groups $(n=8)$. Group A received simvastatin $20 \mathrm{mg}$ twice daily, Group B received gemfibrozil $600 \mathrm{mg}$ twice daily, Group C received acipimox $600 \mathrm{mg}$ twice daily. Each subject performed two 120 minute walks, once with drug, and once with placebo ( 4 days treatment plus a final dose on the morning of the exercise trial). Treatment order was reversed for half of each group.

Compared to placebo, simvastatin treatment, had no impact on fat oxidation $(40.9 \pm 8.6 \%$ vs 40.9 $\pm 9.7 \%$ ), or on plasma concentration of free fatty acids (FFA), glycerol or glucose. Treatment with gemfibrozil, showed lower fat oxidation ( $32.3 \pm 13.9 \%$ vs $39.7 \pm 7.9 \%$ ), and lower plasma concentrations of FFA and glycerol, but differences did not reach significance at the 0.05 level. Acipimox treatment, produced significantly lower fat oxidation $(36.9 \pm 12.8 \%$ vs $50.2 \pm 16.1 \%, P=0.011)$, and lower plasma concentrations of FFA and glycerol $(P=<0.0001$ and $P=<0.0001$, respectively). Plasma glucose showed a trend toward lower values with acipimox $(P=0.088)$. These data demonstrate that selective lipid lowering drugs can reduce fat availability for exercise metabolism, placing increased demands on carbohydrates which may reduce exercise tolerance.

\section{Introduction}

Hypercholesterolaemia is an important risk factor in the development of coronary artery disease. Following favourable results from interventional studies, the use of cholesterol lowering drugs is becoming widespread. ${ }^{1,2}$ In addition to measures aimed at reducing cholesterol levels, patients 'at risk' are often advised to exercise frequently to increase their cardiovascular reserve, help lose weight and improve their sense of well being and thereby reducing their overall risk of coronary heart disease. ${ }^{3}$ We wished to examine whether the aims of increasing exercise and reducing cholesterol using drug therapy are in conflict.

During prolonged aerobic exercise of moderate intensity, much of the required energy is derived from the oxidation of free fatty acids released from adipose tissue ${ }^{4}$ in response to reduced levels of insulin and increased levels of catecholamines, which activate hormone-sensitive lipase. ${ }^{5}$ If this pathway is interrupted, then exercising muscles

Correspondence: M.J. Kendall, M.D., F.R.C.P., Department of Medicine, Queen Elizabeth Hospital, Edgbaston, Birmingham B15 2TH, UK.

Accepted: 5 October 1992 become increasingly dependent on glycogen stores, which when depleted, leads to premature exhaustion. ${ }^{6}$ We have assessed the impact of three commonly prescribed lipid lowering drugs: simvastatin (an HMG-coenzyme A reductase inhibitor), ${ }^{7}$ gemfibrozil (a fibric acid derivative known to stimulate lipoprotein lipase) ${ }^{8}$ and acipimox (a nicotinic acid derivative that inhibits hormonesensitive lipase) ${ }^{9}$

On the basis of previous observations, ${ }^{10,11}$ acipimox would be expected to have an adverse effect on the metabolic response to prolonged exercise. Gemfibrozil and simvastatin, may cause myopathy, ${ }^{12}$ and if taken concurrently can cause rhabdomyolysis, ${ }^{13}$ but little is known of their effects upon exercise metabolism.

\section{Methods}

\section{Subjects}

Twenty-four healthy males aged 19-36 years and $65-97.5 \mathrm{~kg}$ in weight volunteered for this study which was approved by the Central Birmingham Health Authority Research Ethics Committee. All 
subjects were fully informed of the procedures and provided written voluntary consent. Routine clinical and haematological screening revealed no abnormality in any of the subjects recruited to this study. Cardiovascular fitness was assessed by measurement of maximal oxygen uptake during a graded exercise test to exhaustion on a motorized treadmill and all subjects were fully habituated to the protocol and procedures of metabolic measurement during exercise prior to the start of the study.

\section{Experimental design}

The study consisted of three single blind comparisons, with subjects randomly assigned to one of three groups $(n=8)$. In each group one lipid lowering drug was compared to placebo. Group A received simvastatin $20 \mathrm{mg}$ twice daily and placebo; Group B gemfibrozil $600 \mathrm{mg}$ twice daily and placebo; Group C acipimox $250 \mathrm{mg}$ twice daily and placebo. Drugs were taken for a period of 4 days plus a final dose 2 hours prior to the exercise trial on day 5. The treatment order of drug and placebo was reversed for half of the subjects in each group and each exercise trial (drug and placebo) was separated by a period of not less than 14 days. Subjects' dietary and activity patterns were carefully replicated for each 5 day period of the trial.

On the day of the exercise trial (day 5) subjects arrived at the Clinical Investigations Unit having starved overnight and were provided with a fat free, $1 \mathrm{MJ}$ carbohydrate meal 2 hours prior to exercise. A cannula was inserted into a suitable forearm vein for blood sampling and the subject allowed to rest. Basal heart rate, blood pressure and blood were taken 15 minutes and 5 minutes before and blood every 15 minutes during 120 minutes of exercise on a motorized treadmill at an exercise intensity of $50 \%$ of the subjects' previously determined maximal oxygen uptake. Expired air was also collected and the rate perceived exertion (RPE) of the subject recorded every 15 minutes during the exercise period. The subject consumed water $(150 \mathrm{ml}$ every 15 minutes) throughout the exercise to maintain hydration.

\section{Indirect calorimetry}

The measurement of oxygen uptake and carbon dioxide excretion was performed using the Douglas bag technique. Total resistance to flow of the gas collection system was $2.0 \mathrm{~cm}$ of water at a constant flow of $200 \mathrm{l} /$ minute and within the WHO recommendations. ${ }^{14}$ The volume of gas was measured at constant flow using a dry gas meter (Harvard, UK). Aliquots of expired air were analysed for percentage of oxygen and carbon dioxide using a paramagnetic oxygen (Beckmann OM11) and infra-red carbon dioxide meter (Beckmann LB2) previously calibrated with standard gases (BOC Special Gases) certified to an accuracy of $0.05 \%$. Computation of oxygen uptake and carbon dioxide $\stackrel{2}{C}$ excretion was performed using the Haldane transformation ${ }^{15}$ and the rates of energy expenditure, $\stackrel{\vec{O}}{\stackrel{D}{\circ}}$ and the proportion of carbohydrate and fat $\bar{C}$ metabolism calculated using standard equations. ${ }^{16} \frac{\mathrm{O}}{\bar{N}}$

\section{Analytical method}

Blood samples $(5 \mathrm{ml})$ were taken into vacutainers containing potassium oxalate and sodium fluoride, $\stackrel{\square}{\circ}$ a $500 \mu \mathrm{l}$ portion of whole blood removed for the $\overrightarrow{\vec{\omega}}$ measurement of haemoglobin and haematocrit and $\stackrel{\omega}{\mathcal{H}}$ the remainder centrifuged at $5^{\circ} \mathrm{C}$ and the plasma 8 stored at $-70^{\circ} \mathrm{C}$ prior to enzymatic analysis of 3 . glucose,${ }^{17}$ free fatty acids (FFA) ${ }^{18}$ and glycerol. ${ }^{19}$ के All plasma concentrations were corrected for changes in plasma volume. ${ }^{20}$

\section{Calculation and statistical analysis}

The total energy expenditure and percentage con- tribution of carbohydrate and fat to the metabolic $\vec{s}$ mixture for the 120 minutes of exercise was calculated by summation of the values obtained for each 15 minute expired gas sample. The data from $\vec{\oplus}$ these calculations, the heart rate, rate of perceive exertion (RPE) and the measured concentration of blood substrates were analysed by two-wa.y analysis of variance (ANOVA) with repeated measures in both the condition (that is, drug or placebo treated) and time of sampling. The results are presented as means and standard deviations (s.d.).

\section{Results \\ Cardiovascular response and exercise tolerance}

The mean $(n=24)$ maximal oxygen uptake $\left(\mathrm{VO}_{2}\right.$ $\max )$ of $56 \pm 5.3 \mathrm{ml} \mathrm{kg} /$ minute confirmed the subjects as moderately fit but not specifically endurance trained. Randomizing the selection of subjects into groups produced no significant difference in $\mathrm{VO}_{2} \max$ between the groups; $55.6 \pm 4.1$ Group A; $58 \pm 5.2$ Group B; $55.4 \pm 5.7$. Group C. Mean heart rate responses $(n=48)$ to $\mathbb{O}$ steady-state submaximal exercise at $50 \%$ of $\mathrm{VO}_{2} \underset{\mathrm{N}}{\mathrm{N}}$ max were $131 \pm 10$ after 60 minutes and $137 \pm 9$ O after 120 minutes and did not differ significantly either between groups or between drug and placebo trials.

All subjects successfully completed the exercise trial after placebo. Two subjects failed to complete the exercise trial with acipimox terminating the exercise at 105 minutes. One subject failed to 
complete the exercise trial with simvastatin terminating the exercise tests at 105 minutes. In none of these subjects were there any signs of increased oxygen consumption, ventilatory response, heart rate or other objective signs of distress. The subjects did, however, perceive the exercise to be more demanding providing RPE scores that were significantly higher (14vs 10) in response to the drug. The metabolic response of these subjects are considered later.

\section{Energy expenditure and exercise metabolism}

Exercise performed at $50 \%$ of $\mathrm{VO}_{2}$ max for 120 minutes required a mean $(n=48)$ total energy expenditure of $5.04 \pm 6.4 \mathrm{MJ}$ with no significant difference in mean energy expenditure either between groups of subjects for either drug or placebo trials (Table I). The relative contribution of fat as a metabolic fuel increased with duration of exercise from a mean $(n=48)$ of $25.3 \pm 12.8 \%$ after 15 minutes to $52.4 \pm 12.8 \%$ after 120 minutes and was significant for all exercise trials irrespective of $\operatorname{drug}(P=0.0001$; Figure 1$)$. The higher, though not significantly higher, contribution of fat as a metabolic fuel in Group C on placebo was because four subjects in this group showed a consistently greater shift to fat oxidation during exercise.

Compared to placebo the overall contribution of fat as a metabolic fuel during exercise remained unchanged in response to simvastatin but decreased in response to both gemfibrozil and acipimox (Table II). Gemfibrozil reduced fat oxidation during exercise $(7.5 \% ; P=0.211)$, the difference from placebo being greatest $(10.1 \%$; $P=0.1857$ ) after 120 minutes of exercise. Acipimox suppressed overall fat oxidation by $13.3 \%(P=0.011)$. The difference from placebo was most marked during the first 90 minutes of exercise (Figure 1c).

Table I Mean rate of energy expenditure ( $\mathrm{kJ} /$ minute), for Groups A (simvastatin), B (gemfibrozil) and C (acipimox), in drug and placebo conditions (means \pm s.d.)

\begin{tabular}{lccc}
\hline Condition & \multicolumn{3}{c}{$\begin{array}{c}\text { Energy } \\
\text { expenditure } \\
(\mathrm{kJ} / \text { min })\end{array}$} \\
\hline Simvastatin & $\mathrm{n}$ & 42.03 & $s . d$. \\
Placebo & 8 & 42.24 & 0.59 \\
Gemfibrozil & 8 & 41.45 & 0.70 \\
Placebo & 8 & 42.19 & 0.60 \\
$\begin{array}{l}\text { Acipimox } \\
\text { Placebo }\end{array}$ & 8 & 43.42 & 0.31 \\
\hline
\end{tabular}
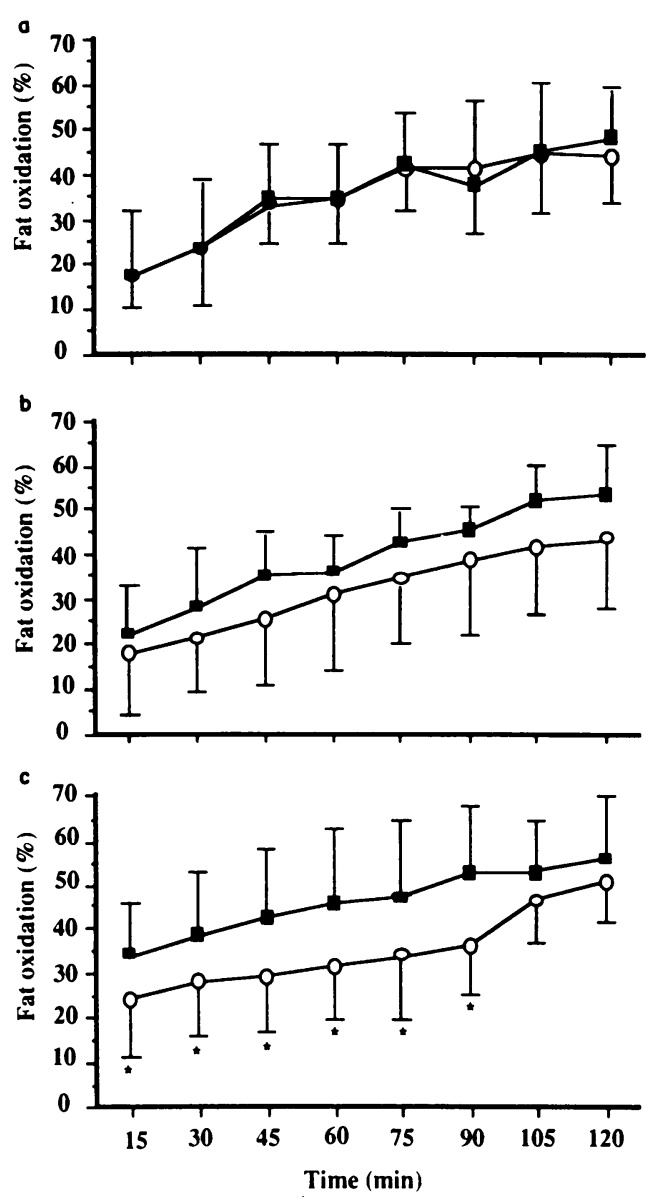

Figure 1 Percentage fat contribution toward total energy expenditure during 120 minutes exercise at $50 \%$ $\mathrm{Vo}_{2}$ max with drug (-O-) and with placebo (- - ) (means \pm s.d.; $n=8$ ). (a) Simvastatin, (b) gemfibrozil, (c) acipimox. *Significantly different between drug and placebo, $P=<0.05$.

\section{Plasma substrate concentrations}

(a) Plasma triglycerides Plasma triacylglycerol (triglyceride) concentration increased significantly $(P=0.0001)$ from rest in all exercise trials (Figure 2). The smaller increase in plasma triacylglycerol concentration from basal levels on drug compared to the placebo were not significant for simvastatin $(P=0.236)$ or gemfibrozil $(P=0.1683)$ but was significant at all time points during exercise for acipimox $(P=0.002)$.

(b) Plasma glycerol and free fatty acids The plasma concentrations (means \pm s.d.) of glycerol and free fatty acids are presented in Figures 3 and 4 , 
Table II Percentage contribution of fat oxidation toward total energy expenditure, for Groups A (simvastatin), B (gemfibrozil) and C (acipimox), in drug and placebo conditions (means \pm s.d.)

\begin{tabular}{lccrc}
\hline Condition & $\mathrm{n}$ & $\begin{array}{c}\text { Fat oxidation } \\
(\%)\end{array}$ & s.d. & ANOVA summary \\
\hline Simvastatin & 8 & 40.6 & 8.6 & $F=0.004, P=0.950$ \\
Placebo & 8 & 40.9 & 9.7 & \\
Gemfibrozil & 8 & 32.2 & 13.9 & $F=1.897, P=0.211$ \\
Placebo & 8 & 39.7 & 7.9 & \\
Acipimox & 8 & $36.9^{*}$ & 12.8 & $F=11.73, P=0.011$ \\
Placebo & 8 & 50.2 & 16.1 & \\
\hline
\end{tabular}

*Significantly different from placebo.
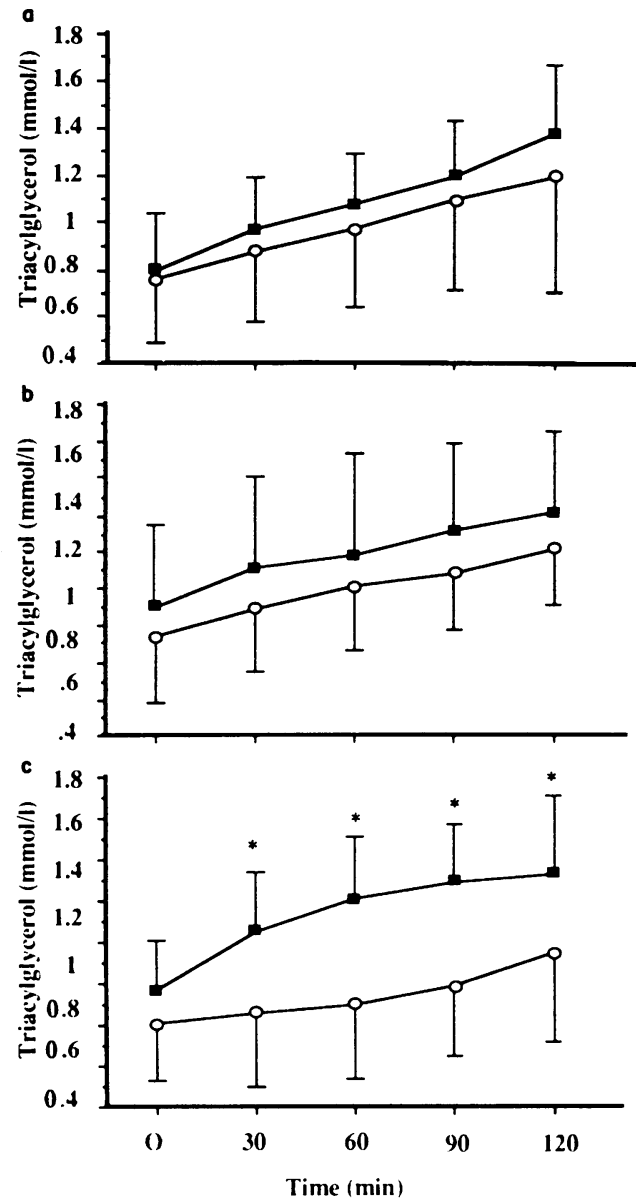

Figure 2 Plasma triacylglycerol concentration (mmol/l) during 120 minutes exercise at $50 \% \mathrm{VO}_{2}$ max with drug $(-\mathrm{O}-)$ and with placebo $(-\square-)$ (means \pm s.d.; $n=8)$. (a) Simvastatin, (b) gemfibrozil, (c) acipimox. * Significantly different between drug and placebo, $P=<0.05$. a

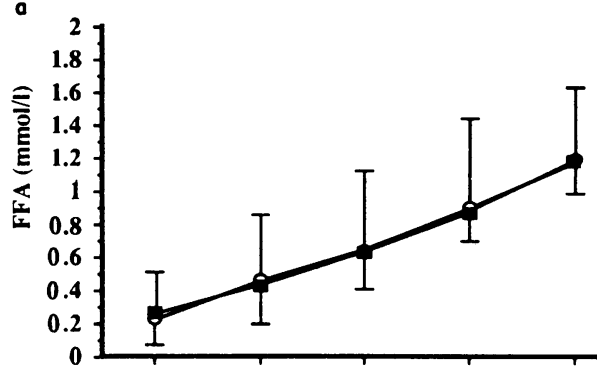$$
\text { b }
$$
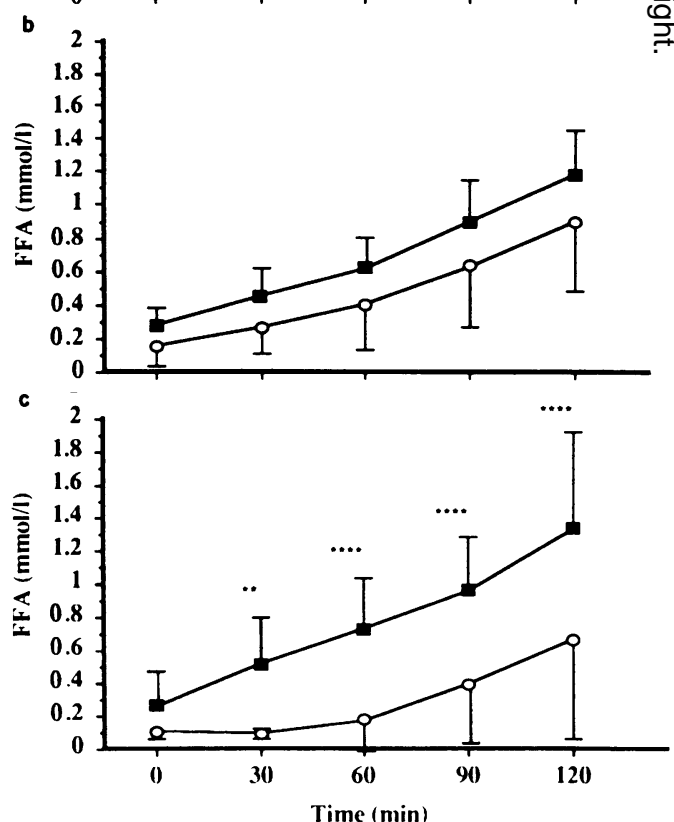

Figure 3 Plasma free fatty acid (FFA) concentration $(\mathrm{mmol} / \mathrm{l})$ during 120 minutes exercise at $50 \% \mathrm{VO}_{2} \max$ with drug (-O-) and with placebo (- - - ) (means \pm s.d.; $n=8$ ). (a) Simvastatin, (b) gemfibrozil, (c) acipimox. ${ }^{* *} P<0.01 ;{ }^{* * * *} P<0.0001$. 
respectively. The resting and exercise concentrations of FFA and glycerol were not significantly altered after simvastatin. Compared to placebo, gemfibrozil reduced the resting plasma concentration of free fatty acids from $0.28 \pm 0.11$ to $0.16 \pm 0.02 \mathrm{mmol} / \mathrm{l}$ and remained $23 \%$ lower than placebo after 120 minutes of exercise $(0.91 \pm 0.42$ vs $1.19 \pm 0.26 \mathrm{mmol} / \mathrm{l})$; though the overall response failed to reach statistical significance $(P=0.129)$. No decrease in plasma glycerol was observed at rest but the rise in plasma glycerol with exercise was lower after gemfibrozil than placebo $(0.53 \pm 0.12$ vs $0.64 \pm 0.10 \mathrm{mmol} / \mathrm{l} ; \quad P=0.089)$. There was virtually no change in either free fatty acids or glycerol from basal levels during the first 60 minutes of exercise after acipimox. Thereafter, plasma free fatty acids and glycerol rose steadily
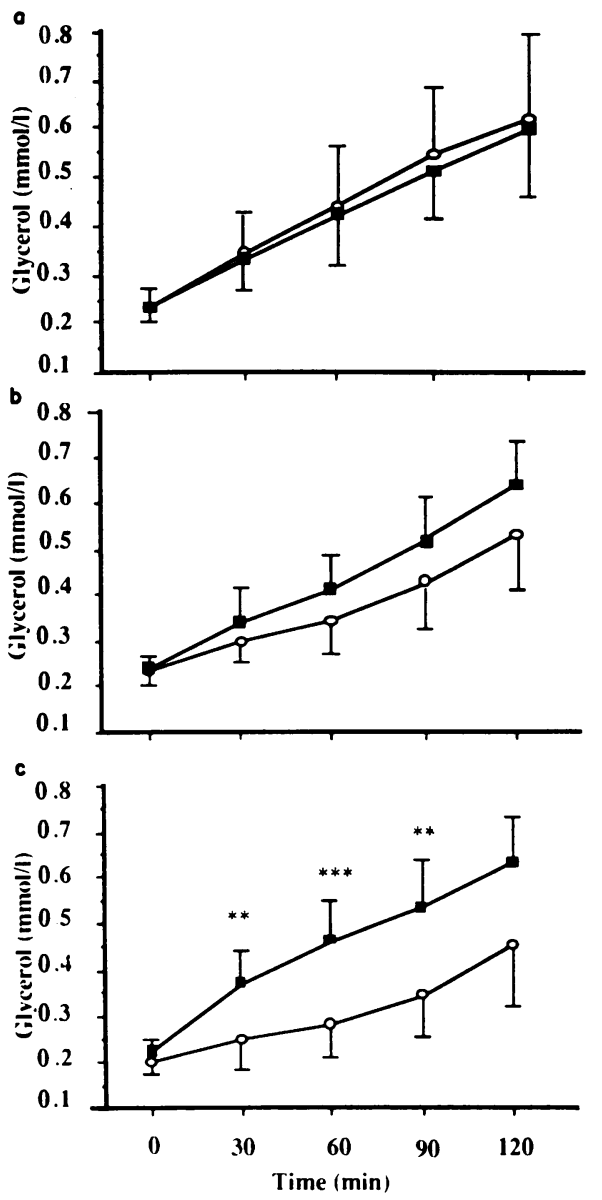

Figure 4 Plasma glycerol concentration ( $\mathrm{mmol} / \mathrm{l})$ during 120 minutes exercise at $50 \% \mathrm{Vo}_{2}$ max with drug (-O-) and with placebo (- - ) (means \pm s.d.; $n=8$ ). (a) Simvastatin, (b) gemfibrozil, (c) acipimox. ${ }^{* *} P<0.01$; *** $P<0.001$ but were still significantly lower than placebo after 120 minutes of exercise $(P=0.0001)$.

(c) Plasma glucose There was no significant difference in basal glucose concentrations between any of the groups on either drug or placebo and no significant difference in response to exercise between drug and placebo for any of the drugs under discussion (Figure 5).

\section{Discussion}

The present study investigated the potential interaction between exercise and a short course of lipid lowering drugs upon the use of fat as a metabolic fuel in normal healthy volunteers. Whole
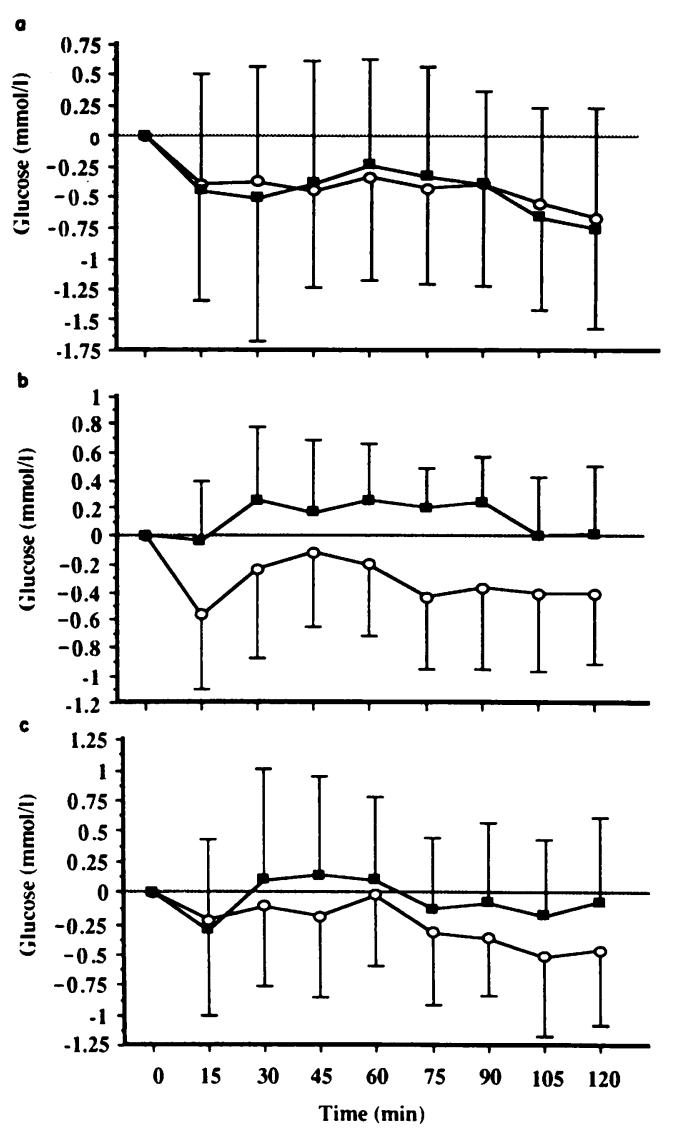

Figure 5 Plasma glucose changes from resting values (mmol/l) during 120 minutes exercise at $50 \% V_{\mathrm{O}_{2}} \max$ with drug (-O-) and with placebo (- - ) (means \pm s.d.; $n=8$ ). (a) Simvastatin, (b) gemfibrozil, (c) acipimox. 
body exercise demanding $50 \%$ of maximal oxygen uptake was chosen as representative of the exercise intensity corresponding to a 'brisk walk'. At this exercise intensity fat provides a major contribution as a metabolic fuel rising significantly throughout the exercise period to greater than $50 \%$ of the required energy expenditure after 120 minutes. The mean total energy expenditure for the exercise trial was $5 \mathrm{MJ}$; significantly less than the estimated carbohydrate energy reserve of $8 \mathrm{MJ}$ available as muscle and liver glycogen of a normal adult male. ${ }^{21}$ In addition the subjects consumed $1 \mathrm{MJ}$ carbohydrate meal 2 hours prior to exercise in order to ensure that liver glycogen stores were restored to normal and that euglycaemia would be maintained throughout the experimental period. These precautions were thought necessary to reduce the impact of a possible hormonal response to decreasing blood glucose during exercise and thus isolate the effect of the drugs under investigation on fat metabolism.

The results of this investigation indicate that a short course of simvastatin had no effect upon substrate metabolism during exercise. The reported mechanism of action of simvastatin is through inhibition of hepatic $\mathrm{HMG}$-coenzyme A reductase, the flux controlling enzyme of cholesterol synthesis..$^{22}$ Previous studies ${ }^{23}$ have shown that a prolonged course of simvastatin is known to have little or no effect upon fat metabolism per se and the present data would support this view. One subject did however fail to complete the 120 minute exercise trial after treatment with simvastatin, stopping after 90 minutes with significantly elevated exertional rating (18vs 14$)$ and a reduction in fat oxidation ( $25.7 v s 49.4 \%)$. The reason for this is not known.

The results obtained with gemfibrozil treatment are of considerable interest but as the changes were

\section{References}

1. Consensus conference statement: lowering blood cholesterol to prevent coronary heart disease. JAMA 1985, 253: 2080-2086.

2. Brown, W.V. Review of clinical trials: proving the lipid hypothesis. Eur Heart $J$ 1990, 11 (Suppl H): 15-20.

3. Morris, J.N., Clayton, D.G., Everitt, D.G., Semmence, A.M. \& Burgess, E.H. Exercise in leisure time: coronary attack and death rates. Br Heart $J$ 1990, 63: 325-334.

4. Ahlborg, G., Gelig, P., Hagenfeldt, L., Hendler, R. \& Wahren, J. Substrate turnover during prolonged exercise in man. J Clin Invest 1974, 53: 1080-1090.

5. Galbo, H. Hormonal and Metabolic Adaptations to Exercise. Thieme-Stratton, New York, 1983, pp. 64-67.

6. Hermansen, L., Hultman, E. \& Saltin, B. Muscle glycogen during prolonged severe exercise. Acta Physiol Scand 1967, 71: $129-139$.

7. Hagemenas, F.C., Pappu, A.S. \& Illingworth, D.R. The effects of simvastatin on plasma lipoproteins and cholesterol homeostasis in patients with Leterozygons familial hypercholesterolaemia. Eur J Clin Invest 1990, 20: 150-157. not significant they should be considered a possible trend which needs to be evaluated further. However, our observations may suggest ways of increasing our understanding of its mechanism of action. It appeared that on gemfibrozil consistently less fat was oxidized than on placebo, and the trend was supported by consistently lower plasma concentrations of FFA. If true, this effect could be explained by either impaired FFA release from adipocytes, or increased metabolism in working muscle. Since the data from indirect calorimetry suggested a reduction in fat oxidation, impaired release of FFA from adipocytes would seem more likely.

Acipimox had a pronounced effect upon the ability to exercise and two subjects failed to complete the exercise test. It is a potent nicotinic acid analogue and is a known anti-lipolytic agent reducing the availability of circulating free fatty acids which supply approximately half of the total o fat oxidized by muscle during prolonged submaximal exercise. ${ }^{24}$ The pronounced shift in exercise metabolism after acipimox towards a greater reliance upon carbohydrate oxidation, an increased glycogen use ${ }^{19}$ and an increased reliance upon intramuscular triglycerides as the source of fuel for the now reduced level of fat oxidation, is the most likely cause of the impairment of exercise tolerance in these subjects.

This study involved healthy males given sho courses of treatment. It has shown that drugs de् have differing effects upon energy substrates, and that the methods used were a reasonable way to study this subject. Further studies are now needed to (a) assess the effects of chronic therapy, (b) to determine the relevance of our observations in a patient population, and (c) to investigate further the biochemical processes modified by these drugs during exercise.

8. Frick, M.H., Elo, O., Haapa, K. et al. Helsinki Heart Study: primary prevention trial with gemfibrozil in middle aged men with dyslipidemia. Safety of treatment, changes in risk factors, and incidence of coronary heart disease. $N$ Engl $J$ Med 1987, 317: 1237-1245.

9. Fucella, L.M., Goldaniga, G., Lovisolo, P., Maggi, E., Musatti, L., Mandelli, V. \& Sirtori, C.R. Inhibition of O lipolysis by nicotinic acid and by acipimox. Clin Pharmacol Ther 1980, 28: 790-795.

10. Bergstom, J., Hultman, E., Jorfeldt, L., Pernow, B. \& Wahren, J. Effect of nicotinic acid on working capacity and metabolism of muscle glycogen in man. J Appl Physiol 1969, 26: $170-176$.

11. Walker, M., Cooper, B.G., Elliott, C., Reed, J.W., Orskov, H. \& Alberti, K.G. Role of plasma non-esterified fatty acids during and after exercise. Clin Sci 1991, 81: 319-325.

12. Jenson, $\mathbf{K}$. Myopathy during treatments with fibrates and lovostatin. Ugeskr-Laeger 1991, 153: 862. 
13. Zimetbaum, P., Frishman, W.H. \& Kahn, S. Effects of gemfibrozil and other fibric acid derivatives on blood lipids and lipoproteins. J Clin Pharmacol 1991, 31: 25-37.

14. Andersen, K.L., Shephard, R.J., Denolin, H., Varnaukas, E. \& Masironi, R. Fundamentals of Exercise Testing. WHO, Geneva, 1971, pp. 58-73.

15. Wilmore, J. \& Costill, D.L. Adequacy of the Haldane transformation in the computation of exercise $\mathrm{VO}_{2}$ in man. $J$ Appl Physiol 1973, 35: 85-89.

16. Consolazio, C.F., Johnson, R.E. \& Pecora, E. Physiological Measurements of Metabolic Functions in Man. McGraw Hill, New York, 1963.

17. Stein, M.W. D-Glucose, determination with hexokinase and glucose-6-phosphate dehydrogenase. In: Bergmeyer, H.U. (ed.) Methods of Enzymatic Analysis. Academic Press, New York, 1963, pp. 117-119.

18. Mulder, C., Schouten, J.A. \& Popp-Snijders, C. Enzymatic colorimetric test for in vitro assay of free fatty acids in serum and plasma. J Clin Chem Biochem 1983, 21: 823-827.
19. Boobis, L.H. \& Maugham, R.J. A simple one step enzymatic fluorometric method for the determination of glycerol in $20 \mu$ of plasma. Clinica Chemica Acta 1983, 132: 173-179.

20. Greenleaf, J.E., Van Beaumont, W., Brock, P.J., Morse, J.T. \& Mangseth, G.R. Plasma volume and electrolyte shifts with heavy exercise in sitting and supine positions. Am J Physiol 1979, 236: R206-R214.

21. Newsholme, E.A. \& Leach, A.R. Biochemistry for the Medical Sciences. Chichester, Wiley, 1983.

22. Alberts, A.W., Chen, J., Kuron, G. et al. Mevinolin: a highly potent competitive inhibitor of HMG-CpA reductase and a cholesterol lowering agent. Proc Natl Acad Sci 1980, 77: 3957-3961.

23. Grundy, S.M. HMG-CoA reductase inhibitors for the treatment of hypercholesterolaemia. N Engl J Med 1988, 31: 24-32.

24. Havel, R.J., Pernow, B. \& Jones, N.L. Uptake and release of fatty acids and other metabolites in legs of exercising men. $J$ Appl Physiol 1967, 23: 90-99. 